
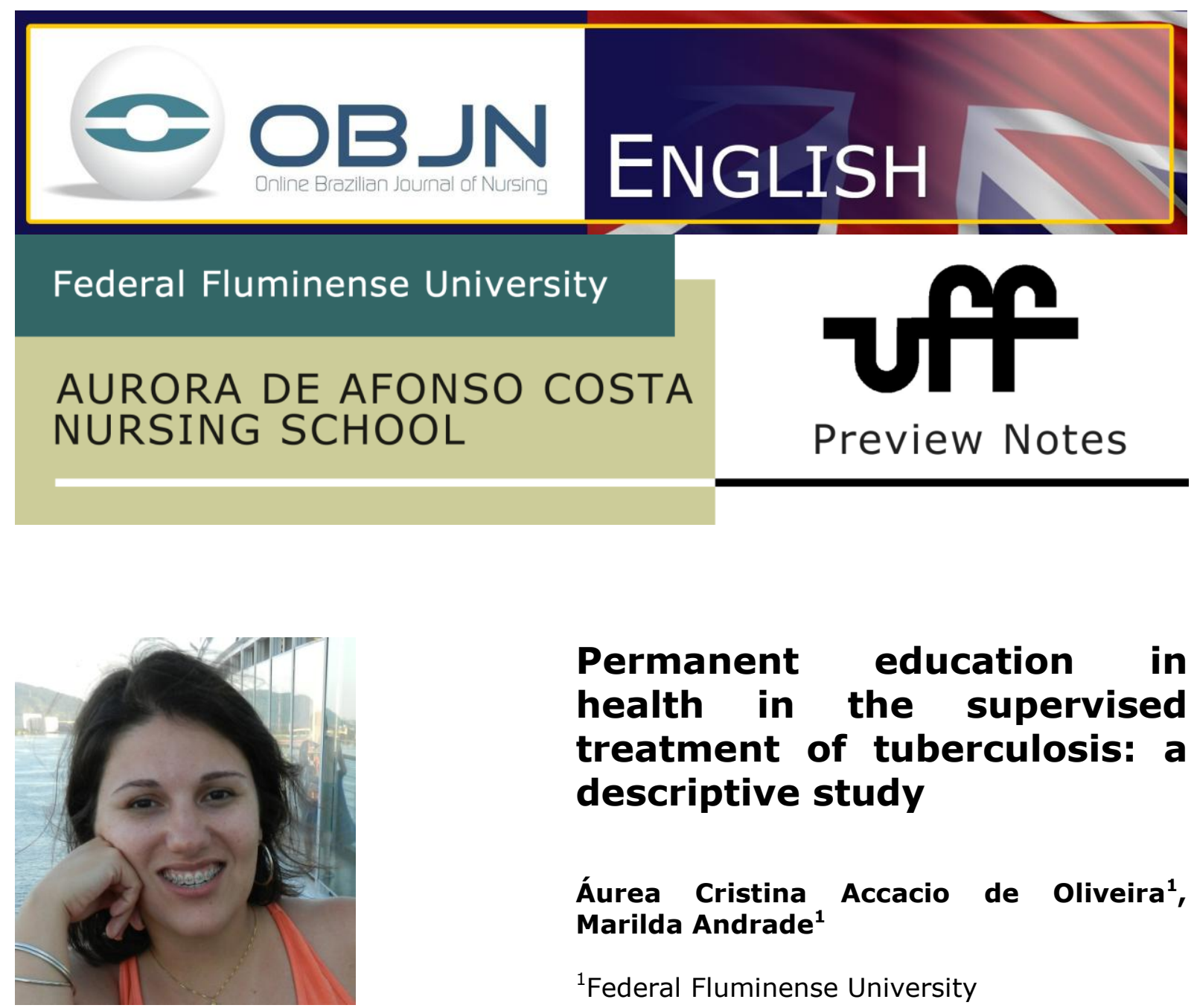

\title{
Permanent education in health in the supervised treatment of tuberculosis: a descriptive study
}

\author{
Áurea Cristina Accacio de Oliveira ${ }^{1}$, \\ Marilda Andrade ${ }^{1}$ \\ ${ }^{1}$ Federal Fluminense University
}

\begin{abstract}
The study focuses on the contribution of permanent education (EP) in teaching Community Health Workers (ACS) about the supervised treatment of tuberculosis. This is a descriptive study with a qualitative approach, aiming to describe the difficulties faced by ACS in the supervised treatment of tuberculosis, and the facilities that are available to them. It aims to discuss the strategies adopted by ACS with regard to performing supervised treatment of tuberculosis. We also aim to propose effective actions in terms of permanent education for ACS with regard to the supervised treatment of tuberculosis. Data collection will be underaken through participant observation and semi-structured interviews with ten ACS of a family health unit in a municipality in the state of Rio de Janeiro, RJ. It is hoped that this study will contribute to the improvement of supervised treatment performed in the city, thus developing quality care and achieving a rate of reduction and the eventual elimination of cases of tuberculosis as recommended by the World Health Organization (WHO).

Keywords: Education, Continuing; Tuberculosis; Community Health Workers
\end{abstract}




\section{RESEARCH PROBLEM AND ITS SIGNIFICANCE}

The interest in this research topic arose through my career as a nurse in the Family Health Strategy Unit (ESF) at Itaboraí. Since I began such work, I began to realize that the municipality had a large number of cases of tuberculosis (TB), which made me think constantly about the strategies employed to control the disease and the effectiveness of such strategies. According to the Ministry of Health (MS), TB is a priority problem in Brazil. With 4,700 deaths per year, it occupies 19th place among the 22 countries responsible for $80 \%$ of all TB cases in the world, and the Rio de Janeiro has among the worst national indicators ${ }^{(1)}$. By 2002, the ESF covered only $20 \%$ of the area of the municipality of Itaboraí, but in the same year, this coverage was expanded to $70 \%$. Even with the increase in the number of health teams, little was mentioned of tuberculosis cases in the area covered by the family health units. In the vast majority of the area, the diagnosed cases had a hospital as gateway for the service, and were not dealt with by family health teams. This fact precluded the development of the Tuberculosis Control Policy in the country, which recommends the need for assistance with regards to the establishment of a decentralized network of diagnosis and treatment, integrated into Primary Health Care, aiming to stimulate activities for surveillance, prevention and control disease. From the perspective of Primary Health Care, these ESF teams were considered the gateway to the healthcare system ${ }^{(1)}$. From 2004 onwards, based on the recommendations of the OMS and $\mathrm{MS}^{(1)}$, the municipality adopted the supervised treatment of tuberculosis by the family health teams, as a strategy to monitor cases of tuberculosis and improve dropout rates with regard to the treatment, besides increasing the number of cures. The participation of community health workers (ACS) was emphasized and became an essential part of the treatment because it enables patients bond with health unity and team. This demonstrates how ACS are of great importance in the monitoring of patients with tuberculosis. In 2007, after years of success in monitoring and curing patients through continuous training, the number of patients treated by health units decreased, and the dropout rate increased alarmingly. This means 
that the training process, previously considered effective, became ineffective, not achieving the expected results. In other words, the training process reversed itself in practice, because, in most cases, the training involved the communication of knowledge within the logic of the "scholar model". It was a means of updating new approaches, and providing new information or new technologies in the implementation of a new policy. This included cases of decentralization or the prioritization of primary care. It involved a gathering of people in a classroom, isolating them from the context of real work, putting them in front of experts to transmit knowledge which, once incorporated, had to be applied $^{(2)}$. Therefore, the reorganization of health care practices cannot be achieved. Without this, concomitantly, we cannot invest in a training policy and establish a process of the permanent training of human resources, whereby the professionals from the family health teams should be encouraged to act with creativity and critical thinking as part of a human, responsible and resolute practice. Such a practice should involve health promotion, disease prevention, and recovery and rehabilitation undertaken in a dynamic and permanent way ${ }^{(2)}$. Education should emerge from practice and from critical reflection, demonstrating the need for constant change and encouraging continuing education on the part of the healthcare team, making it the subject of their educational process and developing new methods and devices aimed at improving their practice ${ }^{(3)}$.

\section{QUESTION}

How can permanent education contribute to the professional development of ACS in terms of effective and high quality practice in the supervised treatment of tuberculosis?

\section{AIMS}

To describe the facilities and the difficulties faced by Community Health Workers in supervising the treatment of tuberculosis; To discuss the strategies adopted by Community Health Workers with regard to the supervised treatment of tuberculosis; To 
propose effective actions with regard to the permanent education of ACS with regard to the supervised treatment of tuberculosis.

\section{METHOD}

Considering that the object of this study is a consideration of the contribution of permanent education in the professional development of ACS with regad to the supervised treatment of tuberculosis, I chose a descriptive form of research and a qualitative approach. Data collection will be conducted in two phases. In the first, we will use participant observation, through educational workshops, in order to approach the context surrounding the subject, and a description of the perceptions of those involved with regard to the subject. In the second phase we will conduct a semi-structured interview to deepen our understanding of some aspects of the observation. Interviews will be held with ten community health workers in a family health unit of a municipality of Rio de Janeiro. The project was submitted to the Ethics Committee on Research involving human subjects, as required by Resolution No. 196/96.

\section{REFERENCES}

1. Ministério da Saúde (BR). Secretaria de Vigilância em Saúde. Departamento de Vigilância Epidemiológica. Programa Nacional de Controle da Tuberculose. Brasília: Ministério da Saúde; 2010.

2. Ministério da Saúde (BR). Secretaria de Gestão do Trabalho e da Educação na Saúde. Departamento de Gestão da Educação em Saúde. Política Nacional de Educação Permanente em Saúde. Série B. Textos Básicos de Saúde, Série Pactos pela Saúde, v. 9. Brasília: Ministério da Saúde; 2009.

3. Godinho J.Tavares C. The Permanent Education in Intensive Care Units: a review article. Online braz j nurs [serial in the internet]. 2009 [cited 2012 June 29]; 8 (2). Available from: http://www.objnursing.uff.br/index.php/nursing/article/view/2288 


\section{PROJECT DATA}

Dissertation from Professional Master Program on Education in Health - UFF. Approved by CEP according to CAAE: 02411712.2.0000.5243, on 07/30/12.

Master student: Áurea Cristina Accacio de Oliveira

Guidance: Marilda de Andrade

Received: 04/07/2012

Approved: 11/09/2012 